\title{
Perioperative morbidity of Vulval cancer
}

\author{
Hanumant V Nipanal ${ }^{1, *}$, Susmitha Shivanna Reddy ${ }^{2}$, Dilip Kumar Mauryya ${ }^{3}$, Ravindra P. Nagendra ${ }^{4}$ \\ ${ }^{\mathbf{1}}$ Assistant Professor, Dept. of Obstetrics and Gynecology, Gadag Institute of Medical Sciences (GIMS), Gadag India, ${ }^{2} \mathrm{PG}$ \\ Student, Dept. of Pathology, BLDE university Vijayapur, Karnataka, India, ${ }^{3}$ Associate Professor, Dept. of Obstetrics and \\ Gynecology, Jawaharlal Institute of Postgraduate Medical Education and Research, Puducherry, India, ${ }^{4}$ Professor and HOD, \\ Dept. of Physiology, Gadag Institute of Medical Sciences(GIMS), India
}

*Corresponding Author

Email: hanumant.1210@rediffmail.com

\begin{abstract}
Introduction: The present study is a retrospective analysis of vulval cancer patients who had been treated with surgery as primary mode. The cases studied were in tertiary care hospital south India of March 2008 to February 2013. Total number of patients was 11 .

Materials and Methods: The medical records of all patients studied retrospectively with reference to stage of the disease, surgery performed, prophylactic antibiotics, intra-operative and postoperative complications.

Results: Among 11 patients 9 were postmenopausal. Ten patients histopathology showed stage $1 \mathrm{~b}$ cancer for whom simple vulvectomy was performed, one patient had co-existing HGSIL( High Grade Squamous Intraepithelial Lesion) and positive right inguinal nodes, requiring $\mathrm{TAH}+\mathrm{BSO}+$ right groin dissection and posterior colporrhaphy was done in one patient with rectocele. One patient presented with stage 2 disease for which radical vulvectomy with bilateral groin lymph node dissection was carried out. Postoperative radiotherapy was given for 8 patients with tumor positive margins.

Conclusion: Even though many modifications in surgical methods of vulval cancer still morbidity is high. Particularly surgical complication of wound infection. This delay will further add up for delay in starting adjuvant treatment. Hence there is a need of further modifications of surgical treatments like minimally invasive approach. A team of oncology surgeons, medical oncologists, radiotherapists is needed to manage this rare cancer.
\end{abstract}

With multidisciplinary approach Surgery for early stage vulval cancer has acceptable morbidity.

Keywords: Carcinoma vulva, Saphenous vein, Vulval cancer.

\section{Introduction}

Carcinoma vulva represents around $4 \%$ of the gynecologic malignancies and $0.6 \%$ of all cancers in women. ${ }^{1,2}$ The carcinoma vulva is rare, about 1.7 per 100000 females. It is mainly disease of postmenopausal women. Average age for invasive carcinoma Vulva ranges from 65 to 70 years. ${ }^{3}$

Etiology is still not clear. But the following factors are often related like

1. Post-menopausal women

2. More common among whites.

3. Increased association with obesity, hypertension, diabetes and nulliparity

4. Associated with vulvar epithelial disorders like lichen sclerosus.

5. Infection with high risk HPV (type 16, 18, 31, 33 and 45) has been detected in patients with invasive cancer vulva.

6. Smoking, other STSs, Syphilis and lymphogranuloma venereum also associated.

The most commonly involved site is labia majora accounting for $50 \%$ of all cases. Next are the labia minora with rare involvement of clitoris and Bartholin glands. Squamous cell cancer type accounts for $90 \%{ }^{4}$ Uremia from ureteric obstruction due to enlarged common ileac and paraaortic nodes, rupture of femoral vessels and sepsis are main causes of death of vulval cancer patients.

There are many modifications in surgery of Vulval
Cancer. ${ }^{5-7}$ Still peri-operative morbidity has been reported up to $50 \% .^{8-9}$

Nowadays, oncological surgeons concern is to minimize radical surgery with similar results to reduce the peri-operative morbidity. ${ }^{10}$ Today three separate vulval and groin incisions were taken instead of radical vulvectomy with bilateral Inguinofemoral lymphadenectomy(IFL). This newer approach decreased in morbidity with comparable survival rate. ${ }^{11-12}$ Complications like Wound cellulitis, wound breakdown and lymphedema reported in $25-39 \%, 17-31 \%$ \& 28 $39 \%$ of the patients respectively. ${ }^{13-15}$

The present study is retrospective analysis of carcinoma vulva cases of 5 year duration from 2008 to 2013 in South India.

\section{Objectives}

1. To study the intra and operative complications of carcinoma vulva patients.

2. To know the peri-operative morbidity of carcinoma vulva patients.

\section{Materials and Methods}

It is a retrospective cohort study of carcinoma vulva patients who had been treated with surgery as a primary mode of treatment. Study period was 5 years. It is conducted at Jawaharlal Institute of Postgraduate Medical Education \& Research (JIPMER), Pondicherry, India form 2008 March to 2013 February. The patients included were carcinoma vulva patients who got 
operated. All patients medical records were collected in data form and analyzed each complications individually. Those included both preoperative and post-operative details. In particular clinical profile of patients, intra operative details like type of surgery, blood loss, and duration of surgery analyzed. Post-operative details like stage of the disease, duration of antibiotics, continuous bladder drainage, wound infection and number of days of hospitalization was studied.

A total of 11 patient's case sheets were studied. Exclusion criteria were a) if patient had not received surgery as primary mode of treatment b) if complete details of case sheet were not available example if patient had taken treatment somewhere and had been referred for a particular morbidity management.

\section{Results}

Among 11 carcinoma vulva patients treated by surgery majority $9(81.82 \%)$ of them were in the age group of $60-80$ years. The minimum age was 48 years and maximum age was 76 years with mean age of 72 years.

\section{Age distribution}

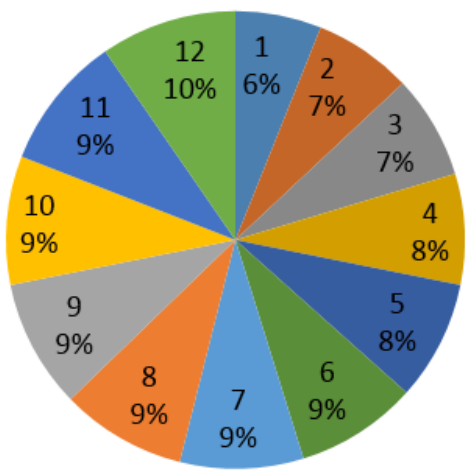

\section{Fig. 1: Age distribution of vulval cancer patients}

Among 11 subjects $9(81.82 \%)$ postmenopausal women and $2(19.28 \%)$ subjects were premenopausal women. All subjects were multi-parous women.

Majority of women $8(72.8 \%)$ presented with pruritus vulva, discharge per vagina $6(54.54 \%)$, bleeding 6 (54.54\%), pain over vulval area $4(36.36 \%)$, growth over vulval area $4(36.36 \%)$ and ulcer over vulva $2(18.18 \%)$.

\section{Clinical presentations}

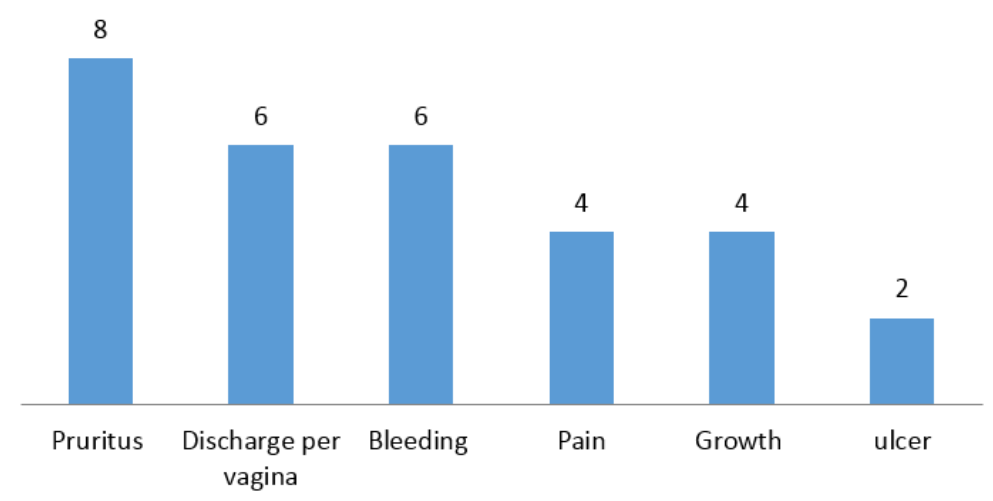

Fig. 2: Clinical presentations of vulval cancer patients

In the present study, 10(90.1\%) women had carcinoma vulva stage $1 \mathrm{~b}$ and $1(9.9 \%)$ patient had c-existing High grade squamous intraepithelial lesion (HGSIL) and positive right inguinal nodes. One patient presented with stage II disease. One patient had rectocele also.

Simple vulvectomy was performed for $10(90.10 \%)$ of stage $1 \mathrm{~b}$ cases. The one case who had co-existing HGSIL and positive right inguinal nodes underwent Total abdominal hysterectomy (TAH+ BSO) and right groin dissection. 
Posterior colporrhaphy was done in 1 patient with rectocele. Radical vulvectomy with bilateral groin lymph node dissection was performed for one patient of stage 2 disease.

\section{Table 1: Histopathological types}

\begin{tabular}{|c|c|c|c|}
\hline Type & Subtype & Number & Percentage \\
\hline $\begin{array}{c}\text { Squamous cell } \\
\text { carcinoma }\end{array}$ & - & 10 & 90.91 \\
\hline & Keratinizing & 8 & 72.73 \\
\hline & Basaloid & 2 & 18.18 \\
\hline Adeno carcinoma & - & 1 & 9.00 \\
\hline
\end{tabular}

All patients received Prophylactic antibiotics. The prophylactic antibiotics were given one hour prior to surgery. The mean blood loss was $345 \mathrm{ml}$ per case. Few cases were anemic at presentation itself. Anemic cases were treated by blood transfusion prior to surgery. Among total 11 cases $3(2.73 \%)$ were received blood transfusion. During surgery $6(5.45 \%)$ patients received blood transfusion.

Average duration of surgery ranged from $105-220$ minutes. Catheters were kept for 7-14 days. Febrile morbidity was seen in $9(81.82 \%)$ patients. Urinary tract infection was seen in $2(18.18 \%)$ patients.

Wound infection of vulva occurred in $6(54.55 \%)$ patients. Vulval wound healing time was average 48 days (range 14-86days). Uneventful cases were discharged by 14 days whereas wound infection cases were hospitalized for average 28 days. 8 (72.73\%) patients had tumor positive margins and were planned for postoperative radiotherapy.

\section{Discussion}

In 1940s, Taussig ${ }^{16}$ introduced butterfly skin incision for the radical vulvectomy and bilateral inguinofemoral lymphadenectomy(IFL). After that so many modified surgical techniques were introduced. The main purpose all surgical modified techniques was to reduce the intra and post-operative morbidity but not compromising the benefits of radical procedure or the survival rate and recurrence rates. Because of which the triple incision procedure was introduced to replace the en bloc surgical excision. ${ }^{5,17}$

Saphenous vein sparing modification was introduced instead of saphenous vein ligation during the inguinal lymphadenectomy when Zhang et al. published their retrospective analysis comparing saphenous vein sparing to saphenous vein ligation during the inguinal lymphadenectomy. That study showed decrease in the development of short-term lower limb phlebitis in shephenous vein preserved limb. ${ }^{18}$

Individual factors like cancer stage, cancer type, patient age and general medical health will affect survival rate. Five-year survival rates for carcinoma vulva are around $78 \%$. Patients with stage I lesions will have five-year survival rate greater than $90 \%$ whereas it decreases to $20 \%$ when pelvic lymph nodes are involved.

The different approach of surgical technique for carcinoma vulva, that is taking separate incisions for tumor and groin dissection procedures, are still having considerable morbidity In the present study, complications were seen in $9(81.82 \%)$ which is similar in comparison with the other studies $73.6 \%,{ }^{14} 76 \%,{ }^{12}$ $85 \%,{ }^{15} 85.7 \% .{ }^{20}$ It was statistically significant. Vulval Wound infection was present in $54.55 \%$ of patients which is significant when compared to $9 \%$ in another series. $^{12}$

Previous studies reported rates of wound breakdown, lymphocyst and limb edema are $9.7-25 \%$, $3.1-27 \%$ and $4.8-21 \%^{12,14,19}$ respectively which when compared to our series of complications were significant. The earlier studies showed wound infection rate of 12.5$27 \% .^{12,14,19}$ Our observation is that relatively high rates of wound infection was due to larger infected primary and poor personal hygiene.

\section{Conclusion}

Even though many modifications in surgical methods of vulval cancer still morbidity is high. Particularly surgical complication of wound infection, wound gaping which will lead to delay in wound healing. This delay will further add up for delay in starting adjuvant treatment. Hence forth decrease in overall disease free survival. Hence there is a need of further modifications of surgical treatments like minimally invasive approach. Such modifications may bring down the present morbidity.With multidisciplinary approach Surgery for early stage vulval cancer has acceptable morbidity. A team of oncology surgeons, medical oncologists, radiotherapists is needed to manage this rare cancer.

\section{Acknowledgements}

I would like to thank Dr. Dilip Kumar Maurrya my teacher for his expert advice and encouragement.

\section{References}

1. Stehman FB. Invasive cancer of the Vulva. In Disaia P, Creasman W. (Eds.) Clinical Gynecologic Oncology. Mosby, 7th edition, 2007. pp.235-64.

2. Jemal A, Murray T, Ward E, et al. Cancer statistics, 2005. CA Cancer J Clin 2005;55:10-30.

3. Ansink A, Vander VJ. Surgical intervention for early squamous cell carcinoma of the vulva (Chochrane Review) In: The Cochrane Library, Issue 4, 2001. Oxford Update Software. 
4. Thomas GM, Dembo AJ, Bryson SC, et al. Changing concepts in the management of vulvar cancer. Gynecol Oncol 1991;42:9-21.

5. Hacker NF, Vander VJ. Conservative management of early vulvar cancer. Cancer 1993;71:1673-4

6. Cavanagh D, Fiarica JV, Hoffman MS, et al. Invasive carcinoma of the vulva: Changing trends in surgical management. Am J Obstet Gynecol 1990;163:1007-15.

7. Burke TW, Stringer CA, Gershenson DM, Edwards CI, Morris M, Wharton JT, et al. Radical wide excision and selective inguinal node dissection for squamous cell carcinoma of the vulva. Gynecol Oncol 1990;38:328-32.

8. Barton DP. The prevention and mangement of treatment related morbidity in vulvar cancer. Best Pract. Res Clint Obstet Gynecol 2003;17:683-701.

9. Hopkin MP, Reid GC, Morley GW: Radical Vulvectomy. The decision for the incision. Cancer 1993;71:1675-1677.

10. Morgan MA, Mikuta JJ. Surgical management of vulvar cancer. Semin Surg Oncol 1999;17:168-72.

11. Gould N,Kamelle S, Tillmanns T et al. Predictors of complications after inguinal lymphadenectomy.

Gynecologic Oncology. 2001;82(2):329-32.

12. Gaarenstroom KN, Kenter GG, Trimbos JB et al. Postoperative complications after vulvectomy and inguinofemoral lymphadenectomy using separate groin incisions.International Journal of Gynecological Cancer. 2003;13(4):522-7.

13. Rouzier R, Haddad B, Dubernard G et al. Inguinofemoral dissection for carcinoma of the vulva: effect of modifications of extent and technique on morbidity and survival. Journal of the American College of Surgeons. 2003;196(3):442-50.

14. Ayhan A, Tuncer ZS, Akarin R et al. Complications of radical vulvectomy and inguinal lymphadenectomy for the treatment of carcinoma of the vulva. Journal of Surgical

15. Oncology 1992;51(4):243-5.

16. Podratz KC, Symmonds RE, Taylor WF. Carcinoma of the vulva: analysis of treatment failures. Am J Obstetric Gynecol 1982;143:340-51.

17. F. J. Taussig, "Cancer of the vulva: an analysis of 155 cases," American Journal of Obstetrics and Gynecology, vol. 40, pp. 764-79, 1940. View at Google Scholar.

18. P. J. DiSaia, W. T. Creasman, and W. M. Rich, "An alternate approach to early cancer of the vulva," American Journal of Obstetrics and Gynecology, vol. 133, no. 7, pp. 825-32, 1979. View at Google Scholar.

19. Zhang, X. Sheng, J. Niu et al., "Sparing of saphenous vein during inguinal lymphadenectomy for vulval malignancies," Gynecologic Oncology, vol. 105, no. 3, pp. 722-6, 2007. View at Publisher · View at Google Scholar · View at Scopus

20. Soliman AA, Heubner M, Kimmig R et al. Morbidity of Inguinofemoral Lymphadenectomy in Vulval Cancer. The Scientific World Journal Volume 2012, Article ID 341253, 4 pages

21. Gurubasavanagud Y, Umadevi K, Uttam D Bafna et all Morbidity following Surgical Management of Vulval Cancer. OJHAS, Vol. 11, Issue 3:(Jul-Sep 2012) 